http://www.hist-edu.ru Историческая и социально-образовательная мысль. Том 10 № 6/1, 2018 Historical and Social-Educational Idea Volume 10 \#6/1, 2018

УДК 316.77; (8: 80:800)

ИБРАХИМ Иман Али

Российский университет дружбы народов

г. Москва, Россия

ТРОФИМОВА Галина Николаевна

Российский университет дружбы народов

г. Москва, Россия

gnt@mail.ru

\section{ХРОНОТОП СОБЫТИЯ В НОВОСТНЫХ ОНЛАЙН-СООБЩЕНИЯХ (ОСВЕЩЕНИЕ СИРИЙСКОГО КРИЗИСА В РОССИЙСКИХ СМИ)}

Статья посвящена исследованию проблемы формирования пространственно-временных координат медиаобраза события, представленного в новостных сообщениях на онлайн-лентах сетевых СМИ. Авторы опираются на исследования ученых из разных стран мира, посвященные проблеме изменения и выявления такого понятия, как хронотоп в литературном тексте. Рассматривая теорию хронотопа, выдвинутую М.М.Бахтиным, через призму журналистской деятельности, авторы выявляют существенные соответствия и возможность применить основные положения этой теории к изучению особенностей освещения события в журналистских текстах. Так, по их мнению, хронотоп кризисного события при его первичном представлении в онлайн-медиапространстве на информационноновостном уровне оповещения обладает специфическими характеристиками, к которым автор относит мультифрагментарное медиаотражение, репрезентативность, повествовательность и семантичность. В результате авторы приходят к выводу о том, что временной компонент хронотопа медиаобраза этого события является устойчивым, но интенсивность его развития подтверждается количеством публикаций в единицу времени. Пространственный компонент хронотопа данного события формируется через те информационные ресурсы, которые сообщают о событии. Максимальное расширение пространства (25 источников) пришлось на 2-й и 8-й часы, а наиболее устойчивыми широкими границами пространство обладало с 8-го по 12-й часы (18-20 источников). Согласно бахтинской теории, надтекстовая сущность хронотопа, а именно «впечатление, которое закрепляется в сознании читателя в процессе восприятия повествовательных стратегий автора», есть, по сути, не что иное, как образ события, формируемый журналистом или журналистами в процессе освещения события в СМИ.

DOI: $10.17748 / 2075-9908-2018-10-6 / 1-109-116$

Iman Ali IBRAHIM

Peoples' Friendship University of Russia

(RUDN University)

Moscow, Russia

Galina N. TROFIMOVA

Peoples' Friendship University of Russia

(RUDN University)

Moscow, Russia

gnt@mail.ru

\title{
THE CHRONOTOPE OF EVENTS IN ONLINE NEWS STORIES (COVERAGE OF THE SYRIAN CRISIS IN THE RUSSIAN MEDIA)
}

The article is devoted to the study of the problem of formation of space-time coordinates of the media image of the event presented in the news reports on the online feeds of online media. The authors rely on the research of scientists from around the world devoted to the problem of changing and identifying such a thing as a chronotope in a literary text. Considering the theory of the chronotope, put forward by M.M.Bakhtin through the prism of journalistic activity, the authors reveal significant correspondences and the possibility to apply the main provisions of this theory to the study of the features of the event coverage in journalistic texts. Thus, in their opinion, the chronotope of the crisis event at its initial presentation in the online media space at the information and news alert level has specific characteristics, to which the author refers multifragmentary media reflection, representativeness, narrative and semantics. As a result, the authors come to the conclusion that the time component of the chronotope of the media image of this event is stable, but the intensity of its development is confirmed by the number of publications per unit time. The spatial component of the chronotope of this event is formed through the information resources that report the event. The maximum expansion of the space (25 sources) was on the $2 \mathrm{nd}$ and 8th hours, and the most stable wide boundaries of the space had from the 8th to the 12th hours (18-20 sources). According to the Bakhtin's theory, the supertext essence of the chronotope, namely, "the impression that is fixed in the reader's consciousness in the process of perceiving the author's narrative strategies", is essentially nothing more than an image of the event formed by a journalist or journalists in the process of covering the event in the media. 
Ключевые слова: хронотоп, повествование, Кеу words: chronotope, narrative, news message, новостное сообщение, интернет-СМИ, ме- Internet media, media image, Syrian crisis, network диаобраз, сирийский кризис, сетевая журна- journalism листика

Для цитирования: Ибрахим И. А., Трофимова For citation: Ibrahim I. A., Trofimova G.N. The chroГ.Н. Хронотоп события в новостных онлайн- notope of events in online news stories (coverage of сообщениях (освещение сирийского кризиса в the Syrian crisis in the Russian media). Historical российских сми). Историческая и социально- and Social-Educational Idea. 2018. Vol. 10. No. 6-1. образовательная мысль. 2018. Том. 10. № 6-1. Рр. 109-116. c. $109-116$. doi: 10.17748/2075-9908-2018-10-6/1-109-116. (in Russ)

В современном обществе, при всех усложнениях и проблемах его взаимодействия с журналистикой, ее ведущей функцией остается функция информирования о событиях. Информационная функция не только не слабеет, но, наоборот, в связи с ростом значимости информации становится все более доминантной, вбирая в себя и элементы развлечения, и элементы воздействия. Если раньше воздействующая составляющая обеспечивалась через аргументацию и объяснение события, то теперь фактологическая основа благодаря своей насыщенности приобретает эффект влияния. Сами сведения о событии оказываются средством влияния на общественное мнение. Как справедливо говорит В.Д. Мансурова, «пространство массовой коммуникации, создаваемое журналистикой, можно рассматривать как пространство конструирования, бытования и трансляции социальных смыслов, мотивирующих социальное действие» [8, с. 45]. Журналистика как важнейший и особый социальный институт выполняет свою главную и постоянную функцию - не только сообщать информацию о событии, но и донести адекватный смысл о событии до аудитории, которая в условиях хаоса глобальных информационных потоков не имеет времени на самостоятельное осмысление, несмотря на то, что именно сетевые СМИ дают возможность критического подхода к предоставляемой информации. За короткое время событие получает мультифрагментарное медиаотражение в хаотически появляющихся информационных сообщениях, которые О.В. Романов определяет как распыленные, раздробленные, разбросанные [13, с. 55]. Так, вместо полноценной всесторонне представленной картины события, информация о нем в интернете оказывается фрагментарной, обрывочной, бессистемной и - как следствие - недостоверной или искаженной. Отрывочные сведения становятся, по выражению Д.В. Ольшанского, «исключительно осколочными сообщениями», порождающими и укрепляющими «иллюзии всеобъемлющего знания о мире и происходящих в нем событиях» [11, с. 20]. В процессе хаотического нагромождения информационных сообщений о кризисном событии в первые сутки после него, по справедливому замечанию В.В. Витвинчука, «множатся микрособытия, нелегитимно присваивающие себе информационную актуальность основного события и увеличивающие уровень псевдособытийности» [3, с. 108]. Рассуждая об объективности при конструировании медиасобытия, та же В.Д. Мансурова отмечает, что «картина мира, формируемая средствами массовой информации, далеко не адекватна объективной реальности» $[10$, с. 87].

Хронотоп кризисного события при его первичном представлении в онлайнмедиапространстве на информационно-новостном уровне оповещения обладает специфическими характеристиками. В XX веке фокус научных исследований в филологии и смежных науках смещается на приоритетность речевого функционирования языка в его опоре на диалогические высказывания, характеризующиеся оценочностью (Выготский [3]; Якубинский [15]). История развития информационного предъявления кризисного события в сообщениях на новостных онлайн-лентах обладает особым хронотопом, который воплощается в информационном пространстве, формируемом новостными лентами в период первых суток с момента события. Интересно, что Т.А. Дронова видит в хронотопе «... психологический конструкт, образовавшийся в определенное время в определенном месте с большим выделением психофизической энергии и привнесением особо определяющего смысла» [5, с. 206-207], что приближает идею хронотопа к основным постула- 
там теории журналистики. Его временная составляющая определяется скоростью появления сообщений, а пространственная - локализуется широтой перечня интернетресурсов, участвующих в освещении события. Базовый образ материала концентрирует смысл и определяет эволюцию медиасобытия. Пространственно-временные маркеры хронотопа акцентируют внимание аудитории на быстро сменяющихся фрагментах, как говорит В.В. Витвинчук, «автор интерпретирует время, ускоряя или замедляя его, и создает индивидуальный хронотоп материала». Коллективный автор - создатель медиаобраза события на новостных лентах - формирует обобщенный хронотоп этого события. Об этом же говорит и В.В. Хорольский: «никакой медийный факт не равен факту жизненному» и «никакой медийный факт невозможно отделить от мнения о нем» [14, с. 80]. Создатель медиатекста наполняет медиасобытие своим ощущением времени и пространства, то есть определяет его хронотоп [2, с. 109]. Следовательно, медиатекст, повествующий о медиасобытии, нельзя воспринимать как документальное свидетельство о событии реальном: это модель действительности, полученная в процессе творческой деятельности журналиста, объект его текстовой деятельности [5, с. 38]. Вполне перекликается с пониманием хронотопа в текстах интернет-журналистики и мнение М.В. Лукова, который считает, что «пространственно-временной континуум телевизионной картины мира неизбежно стягивается к одной точке под названием "здесь и сейчас", что и служит, в свою очередь, доминантой культуры повседневности, отражаемой телевидением и конструируемой им» [7].

В то же время компьютерные и информационные технологии привели к тому, что в сетевой медиасфере информирование аудитории претерпевает качественные изменения. Резко увеличилось количество практически единовременных сообщений, которые публикуются многочисленными новостными лентами интернет-СМИ. Особенно наглядно это видно на примере освещения кризисных событий в горячих точках планеты. Такие кризисные события, как сирийский конфликт, имеют особую общественно-политическую значимость, и это проявляется в том, что информационное поле, на котором формируется информационная картина события, оказывается крайне разнородным. Одно событие получает множество отражений, количество которых достигает пика в течение нескольких часов после события, а затем на протяжении суток постепенно сходит на нет. Тем самым можно рассматривать временную составляющую в комплексном представлении целостной информационной картины события. Время становится важным фактором ее формирования.

Так же активно расширяется и география интернет-ресурсов, позволяющая говорить о пространстве информационной картины кризисного события. Несмотря на давно декларированную ликвидацию пространственных ограничений в Интернете, информационное онлайн-пространство также становится устойчивым понятием, которое используется многими исследователями для определения особой онлайн-сферы формирования и функционирования информации.

Тем самым мы можем говорить об особом хронотопе отражения события на новостном информационном поле онлайн-СМИ.

Понятие хронотопа (в переводе с древнегреческого chronos - это время, a topos - это пространство) было разработано известным филологом М.М. Бахтиным в литературоведении XX века по поводу пространственно-временной актуализации событий в художественном тексте. По мнению М.М. Бахтина, «хронотоп определяет художественное единство литературного произведения в его отношении к реальной действительности» $[1, \mathrm{c}$. 391]. М.М. Бахтин подчеркивает, что хронотоп как формально-содержательная категория организует структуру текста и присваивает ему эмоционально-ценностную окраску пространственно-временных взаимоотношений: «всякое вступление в сферу смыслов свершается только через ворота хронотопов» [1, с. 399]. Идея о том, что хронотоп воспроизводит пространственно-временную картину мира и организует композицию произведения, безусловно, может быть распространена не только на художественную литературу, но и на журналистские тексты. Действительно, пространственно-временные параметры определяют все существование человечества (время как четвертое измерение пространства). 
Любое событие имеет время и место, что составляет важнейшую часть фактологической основы новостного сообщения (где происходит или произошло и когда произошло или будет происходить). В аспекте журналистики интересны и размышления М.М. Бахтина о том, что хронотоп имеет изобразительное значение, «время приобретает ... чувственнонаглядный характер, а сюжетные события в хронотопе конкретизуются ... Это и создает возможность строить изображение событий в хронотопе [1, с. 406]. Динамичность, образность и формирование информационной картины события в его развитии составляют хронотопическую основу журналистского текста, в котором отражается окружающий мир. Важно и то, что реальное событие бесконечно множится в сотнях новостей, и его хронотоп складывается в процессе появления в Интернете все новых информационных сообщений из разных информационных источников. При этом формируются два хронотопа: один - хронотоп самого события и второй - совокупный хронотоп новостных сообщений, которые рассказывают об этом событии. В этом взаимодействии формируется полная, целостная и нераздельная информационная картина, осмысливая которую получатели информации благодаря хронотопу не только ее присваивают, но и оценивают.

Хронотоп события, представленного в интернет-СМИ, обладает особыми характеристикам. Кроме коллективного авторства, «цифровые технологии создания и трансляции контента многократно усиливают эффект этого хронотопа, «дробя» или «растягивая» время: актуализируемые события, далеко отстоящие друг от друга по времени, предстают в Интернете в формате «здесь и сейчас» как равноправно бытующие в одной длительности [12]. В широком смысле категории пространства и времени организуют все бытийное пространство человека, общества и окружающего мира.

Время и пространство, по существу, являются опорными категориями для восприятия окружающего мира и структурирования знаний о нем. В аспекте хронотипического осознания мира событие рассматривается как единица диалогического характера: «какое-либо событие происходит только тогда, когда имеет место какое-либо другое событие, сравнение этих событий выявляет факты изменений во времени и пространстве» [6]. Созвучными ведущим критериям журналистской деятельности являются и замечания М.М. Бахтина о важности хронотопов как участников в формировании сюжета текста (в журналистике - сюжета события в журналистском тексте), о наличии у хронотопа повествовательного, репрезентационного и семантического значений [1, с. 400]. Именно журналистские публикации и повествуют о событии, и репрезентируют его, и формируют его семантику с определенными коннотациями. Причем, согласно бахтинской теории, надтекстовая сущность хронотопа, а именно «впечатление, которое закрепляется в сознании читателя в процессе восприятия повествовательных стратегий автора», есть, по сути, не что иное, как образ события, формируемый журналистом или журналистами в процессе освещения события в СМИ.

Пространство новостного онлайн-сообщения определяется количеством и особенностями тех сетевых СМИ, которые опубликовали информацию о событии. Это пространство уникально для каждого события, так как СМИ реагируют на событие по-разному в зависимости от времени. Оно гибко сжимается и расширяется в течение первых суток, что обусловило схожесть хронотопов в литературном художественном произведении и в журналистском обобщении комплексного освещения событий в «горячих точках».

Широкий спектр источников, оперативно откликающихся в Интернете на событие, демонстрирует большие возможности в определении параметров пространственного измерения этого события. Они определяются количеством и уровнем интернет-ресурсов, освещающих событие в определенный фрагмент времени. Точкой отсчета следует считать первое сообщение. Причем его источник вовсе не самый передовой в рейтингах информационных агентств. 29 апреля в 23.45 на сайте Rusvesna.su публикуется сообщение «МОЛНИЯ: Израиль нанес удар по Сирии». На следующий день к 10 часам Яндекс формирует список сообщений по поводу этого события, состоящий из 165 новостных публикаций.

Хронотоп медиаобраза события состоит из двух равноправных, взаимосвязанных и взаимообусловливающих компонентов: пространство и время. 
Пространство медиаобраза события строится на основе охвата источников, сообщающих о нем. За 1-й час отреагировали 9 источников, за 2-й - 25, за 3-й - 8, за 4-й - 11, за 5-й - 7, за 6-й - 4, за 7-й - 10, за 8-й - 22, за 9-й - 16, за 10-й - 17, за 11-й - 16, за 12-й - 10, за 13-й - 5, за 14-й - 4, за 15-й - 2, а затем - по 1-2 сообщения в час до 23:45 включительно.

Пространственный компонент хронотопа данного события формируется через те информационные ресурсы, которые сообщают о событии, и развивается следующим образом:

1. 23:45-00:45 - Rusvesna, Вести.Ru, Life.ru, РИА Новости, Российская газета, Федеральное агентство новостей, НТВ, Коммерсантъ;

2. 00:45-01:40 - Взгляд.Ру, РИА Новости, Федеральное агентство новостей, iReactor (2), Life.ru,, TACC, Полит.эксперт, Телеканал 360, Народные новости, Политика сегодня (2), Известия, Экономика сегодня (3), Федеральное агентство новостей, New Inform, Политэксперт, Пятый канал, ДВ-Росс, RT на русском, Федеральное агентство новостей, Московский комсомолец, Аргументы и факты, News.ru;

3. 01:40-02:31 - РБК, Народные новости, Мона Виста, Интерфакс, ИА REX, TACC, Москва-Баку.ru, REGNUM, Lenta.ru;

4. 02:46-03:44 - iReactor, Комсомольская правда, Газета.Ru, URA.Ru, New Inform, Эхо Москвы, Политэксперт, Инфорос, Российская газета, Комсомольская правда, РИА Новости;

5. 04:02-05:44 - Алтапресс, АМТЕЛ, Хакассия-Информ, Капитал страны, Мойка 78, Ведомости, Южный Федеральный, Военное обозрение, Известия, Федерал Пресс, Московский комсомолец;

6. 06:07-06:34 - Военное обозрение, Известия, Федерал Пресс, Московский комсомолец;

7. 06.59-07:35 - Evo-Rus.com, Sputnik-Таджикистан, Царьград, Ura.Ru, Discover 24, Росбалт, Говорит Москва, Рен ТВ, Российский диалог;

8. 07:47-08:43 - Российская газета, Версия Инфо, Speed Ме, ТК Звезда, Известия, Взгляд.Рy, News.ru, Islam.News, Федеральное агентство новостей, Эхо Москвы, Sputnik Латвия, Kazanfirst.ru, Российский Диалог, ВладТайм, Газета.Ru, Суть событий, ТК Звезда, VSE 42 Новости, Утро.ru, Коммерсантъ, OAnews, Москва-Баку.ru;

9. 08:47-09:45 - Говорит Москва, Москва 24, Эхо Москвы, Свободная Пресса, Радио Маяк, РИА Новости, Вечерняя Москва, News Inform, Инфорос, Известия, РИА Новости, Полит.Py, Daily Storm, DR.RU, Новое время-The New Times, РИА Новости Крым, iReactor;

10. 09:46-10:42 - Дождь, Экономика сегодня, Реальное время, RT на русском, РЕН ТВ, Комсомольская правда, Национальная служба новостей, ТАСС, Пятый канал, Apartment.Ru, Наш формат, Rambler News Service, Журналистская правда, Новые Известия, Аргументы и факты, Агентство Телеграф, Газета.Ru;

11. 10:50-11:44 - Snob.ru, Мир новостей, Новая газета, Sputnik Узбекистан, Эхо Москвы, Свободная Пресса, Гражданские силы.ру, Политэксперт, Телеканал RTV1, Труд, Московский комсомолец, Вести.Ru, Sputnik Литва, Росбалт, Наша версия, ТВ Центр,;

12. 11:50-12:45 - Известия, Вечерняя Москва, Ридус, Ruposters.ru, Советская Россия, Sputnik Армения, Первый канал, Sputnik Молдова, Sputnik Таджикистан, Федеральное агентство новостей;

13. 12:46-13:38 - Грани.Рy, RuNews24.ru, Комсомольская правда, ИА REX, Царьград;

14. 13:48-14:06 - REGNUM, Национальная служба новостей, Интерфакс, Татар-информ;

15. 14:47-15:44 - BFM.ru, Федеральное агентство новостей.

Так, максимальное расширение пространства пришлось на 2-й и 8-й часы, а наиболее устойчивыми широкими границами пространство обладало с 8-го по 12-й часы. Также следует отметить период с 3-го по 5-й часы. С 13-го часа пространство постепенно и последовательно сокращалось. 
В то же время следует обратить внимание и на сами источники, формирующие хронотоп данного кризисного события. Важно проследить частотность сообщений отдельных интернет-ресурсов. По количеству сообщений о событии среди них лидирует «РИА Новости» (11, из них 6 - свои и 5 - ссылки на этот источник в других источниках), «Спутник», который в разных регионах опубликовал 9 сообщений. На 3-м месте - новостная лента ФАН (8). В них формируется наиболее полная и последовательная, а следовательно, объективная информационная картина события. Затем следует «Комсомольская правда» (6). «Эхо Москвы», ТАСС и Известия возвращались к этому событию по 5 раз. По 4 сообщения у таких ресурсов, как «Газета.Ру», «Экономика сегодня», PEH TB, IReactor и «Политэксперт»; 7 источников отреагировали на развитие события по 3 раза: «Rusvesna.su», «Российская газета», «Коммерсантъ», «Интерфакс», «Московский комсомолец», «New Inform» и «News». Наконец, по 2 сообщения выложили 10 источников: «Вести.Ru», «Взгляд.Ру», «Журналистская правда», «Говорит Москва», «Царь-град», «UAREX», «REGNUM», «ТК Звезда», «Инфорос» и «Народные новости». В условиях трансформации работы информационных агентств и новостных лент под воздействием компьютерных и информационных технологий их новостные сообщения соединяются в новостном потоке в единую многоуровневую, многокомпонентную информационную картину события. Все сообщения, собранные на одном информационном ресурсе, складываются в целостный мультимедийный журналистский текст информационной направленности с оценочной коннотацией и объединяющим их хронотопом.

Итак, временной компонент хронотопа медиаобраза этого события является устойчивым, но в то же время интенсивность его развития подтверждается количеством публикаций в единицу времени. Наиболее эффективными с точки зрения выдачи информации становятся второй и восьмой часы после события. Немного менее интенсивными становятся девятый, десятый и одиннадцатый часы. Еще меньше активности приходится на четвертый и двенадцатый часы. В то же время минимальное количество упоминаний приходится на шестой и пятнадцатый часы.

Хронотоп информационного сообщения о кризисном событии в Сирии выстраивается неравномерно. Это создает угрозу достоверности информационной картины и мешает аудитории получать полноценную, объективную информацию. Однако наиболее активную позицию в развитии хронотопа занимают такие авторитетные высоко рейтинговые информационные ресурсы, как РИА Новости, Спутник, Федеральное агентство новостей, Комсомольская правда, ТАСС и Известия, которые обладают высокой степенью доверия аудитории, что позволяет надеяться на то, что картина события получается все же достоверной.

Хронотоп комплексного освещения события в новостном онлайн-потоке приобретает такие важные признаки, как репрезентативность, повествовательность и семантичность.

\section{БИБЛИОГРАФИЧЕСКИЕ ССЫЛКИ}

1. Бахтин М.М. Формы времени и хронотопа в романе: Очерки по исторической поэтике // Бахтин М.M. Вопросы литературы и эстетики. - М.: Художественная литература, 1975. C. 234-407.

2. Витвинчук В.В. Конструирование медиасобытия: специфика социального хронотопа // Вестник Томского государственного университета. (Сер.: Филология). - 2013. - № 2(22). - С. 104-110.

3. Выготский Л.С. Мышление и речь // Выготский Л.С. Избранные психологические исследования. - М., 1956. - 218 с.

4. Дронова Т.А. Хронотопичность стиля мышления в контексте образа // Мир психологии. 2009. - № 4. - С. 35-39.

5. Кожанова В.Ю. Рецептивный аспект создания медиатекста // Вестник Адыгейского государственного университета. (Сер. 2: Филология и искусствоведение). - 2011. - № 2. - С. 4451. 
6. Кудряшов И.А., Бессонова Т.М. Концепция М.М. Бахтина: история, сферы применения и перспективы исследования // URL: http://www.lingexpert.ru/conference/langlaw4/kudryashov_bessonowa.html (дата обращения: 11.11.2018).

7. Луков M.Е. Телевидение: телевизионная картина мира // URL: http:// www.zpu-journal.ru/ e-zpu/ 2008/4/Lukov_TV_World-view/ (дата обращения: 02.10.2017).

8. Мансурова В.Д. «Медийный» человек российской провинции: динамика социального взаимодействия. - Барнаул: Изд-во Алт. гос. ун-та, 2011. - 207 с.

9. Мансурова В.Д. «Медийный» человек как проекция дигитальной онтологии // Филология и искусствоведение. - 2010. - № 3. - С. 116-120.

10. Мансурова В.Д. Журналистская картина мира как фактор социальной детерминации. - Барнаул: Изд-во Алт. гос. ун-та, 2002. - 237с.

11. Ольшанский Д.В. Психология масс. - М.: Академический проект, 2003. - 376 с.

12. Рабкина H.B. Медиасобытие в интернет-хронотопе: В.B. Путин и «кольцо рыбака» // URL: https://cyberleninka.ru/article/n/mediasobytie-v-internet-hronotope-v-v-putin-i-koltso-rybaka (дата обращения: 02.03.2018).

13. Романов О.В. Онтологические и гносеологические проблемы философии Интернета: генезис и синтез фундаментальных идей: Дис. ... канд. филос. наук. - Иваново, 2003. - 153 с.

14. Хорольский В.В. Коммуникативистика и теория журналистики в контексте медийной глобализации: методологические загадки // Вестник Волгоградского государственного университета (Серия 8: Литературоведение. Журналистика). - 2009. - Вып. 8. - С. 78-89.

15. Якубинский Л.П. О диалогической речи // Якубинский Л.П. Язык и его функционирование: Избранные работы. - М., 1986. - С. 38-66.

\section{REFERENCES}

1. Bahtin M.M. Formy vremeni i hronotopa v romane: Ocherki po istoricheskoj poehtike [Forms of time and chronotope in the novel: Essays on historical poetics]. Bahtin M. M. Voprosy literatury $\mathrm{i}$ ehstetiki = Questions of literature and aesthetics M.: Artist. lit., 1975. Pp. 234-407. (InRuss)

2. Vitvinchuk V.V. Konstruirovanie mediasobytiya: specifika social'nogo hronotopa [Construction of the media event: the specifics of the social chronotope] Vestnik Tomskogo gosudarstvennogo universiteta. (Seriya: Filologiya) = Bulletin of Tomsk state University. (Series: Philology). 2013. № 2(22). Pp. 104-110. (InRuss)

3. Vygotskij L.S. Myshlenie i rech' [Thinking and speech] Vygotskij L.S. Izbrannye psihologicheskie issledovaniya = Selected psychological studies. M., 1956. 218 p. (InRuss)

4. Dronova T.A. Hronotopichnost' stilya myshleniya v kontekste obraza [Chronotopicity of the style of thinking in the context of the image]. Mir psihologii = World of psychology 2009. № 4. Pp. 3539. (InRuss)

5. Kozhanova V.YU. Receptivnyj aspekt sozdaniya mediateksta [Receptive aspect of media text creation] Vestnik Adygejskogo gosudarstvennogo universiteta. (Seriya 2: Filologiya i iskusstvovedenie) = Bulletin of Adyghe state University. (Series 2: Philology and art history). 2011. № 2. Pp. 44-51. (InRuss)

6. Kudryashov I.A., Bessonova T.M. Koncepciya M.M. Bahtina: istoriya, sfery primeneniya i perspektivy issledovaniya. [M. M. Bakhtin's concept: history, fields of application and prospects of research] Available at: http://www.lingexpert.ru/conference/langlaw4/kudryashov_bessonowa.html (accessed:: 11.11.2018).

7. Lukov M.E. Televidenie: televizionnaya kartina mira. [Television: television picture of the world] Available at: http:// www.zpu-journal.ru/ e-zpu/ 2008/4/Lukov_TV_World-view/ (accessed: 02.10.2017).

8. Mansurova V.D. «Medijnyj» chelovek rossijskoj provincii: dinamika social'nogo vzaimodejstviya. ["Media" person of the Russian province: dynamics of social interaction]. Barnaul: Izd-vo Alt. state University, 2011. 207 p. (InRuss)

9. Mansurova V. D. Media " man as a projection of digital ontology. Philology and art history Filologiya i iskusstvovedenie $=$ Philology and art history. 2010. № 3. Pp. 116-120. (InRuss)

10. Mansurova V.D. ZHurnalistskaya kartina mira kak faktor social'noj determinacii. [Journalistic picture of the world as a factor of social determination] Barnaul: Izd-vo Alt. state University, 2002. 237 p. (InRuss)

11. Ol'shanskij D. Psihologiya mass. [Mass psychology] M.: Akademicheskij proekt = Academic project, 2003. 376 p. (InRuss) 
12. Rabkina N. V. Mediasobytie v internet-hronotope: V. V. Putin i «kol'co rybaka» Available at: https://cyberleninka.ru/article/n/mediasobytie-v-internet-hronotope-v-v-putin-i-koltso-rybaka (accessed:: 02.03.2018)

13. Romanov O.V. Ontologicheskie i gnoseologicheskie problemy filosofii Interneta: genezis i sintez fundamental'nyh idej: dis. ... kand. filos. nauk. [Ontological and epistemological problems of Internet philosophy: Genesis and synthesis of fundamental ideas: PhD thesis] Ivanovo, 2003. 153 p. (InRuss)

14. Horol'skij V.V. Kommunikativistika i teoriya zhurnalistiki v kontekste medijnoj globalizacii: metodologicheskie zagadki [Communicativistics and theory of journalism in the context of media globalization: methodological riddles 2009.] Vestnik Volgogradskogo gosudarstvennogo universiteta. (Seriya 8: Literaturovedenie. ZHurnalistika) = Bulletin of Volgograd state University. (Series 8: Literary Studies. Journalism.) 2009. Vol. 8. Pp. 78-89. (InRuss)

15. YAkubinskij L.P. 0 dialogicheskoj rechi [About dialogical speech]. YAzyk i ego funkcionirovanie: Izbrannye raboty = Language and its functioning: Selected works. M., 1986. Pp. 38-66. (InRuss)

\section{Информация об авторах:}

Ибрахим Иман Али, соискатель, Российский университет дружбы народов,

г. Москва, Россия

Трофимова Галина Николаевна, доктор филологических наук, профессор, профессор кафедры массовых коммуникаций, филологический факультет, Российский университет дружбы народов,

г. Москва, Россия

gnt@mail.ru

Получена: 11.11 .2018

\section{Information about the authors:}

Iman Ali Ibrahim, Applicant, Peoples' Friendship University of Russia (RUDN University), Moscow, Russia

Galina N. Trofimova, Doctor of Philological Sciences, Professor, Professor of Mass Communications Department, Philological Faculty, Peoples' Friendship University of Russia (RUDN University), Moscow, Russia gnt@mail.ru

Received: 11.11 .2018 